\title{
Near Surface Embedded Application for FRCM Strengthening of RC Beams in
} Flexure

\author{
HossamEldin El-Sherif \\ hossameldin.elsherif@qu.edu.qa \\ Department of Civil and Architectural Engineering, Qatar University, Doha, Qatar \\ Usama Ebead \\ uebead@qu.edu.qa \\ Department of Civil and Architectural Engineering, Qatar University, Doha, Qatar
}

\begin{abstract}
In this paper, the efficacy of a recent strengthening technique, referred to as Near Surface Embedded(NSE), has been investigated for flexural strengthening of Reinforced Concrete (RC) beams using Fabric Reinforced Cementitious Matrix (FRCM). The process of applying NSE-FRCM strengthening technique involves removing the concrete layer at the beam's soffit (being the most deteriorated), which is then replaced by the FRCM composite. In this study, seven RC beams were constructed and tested under four-point loading considering two test variables, namely, (a) FRCM material (Polyparaphenylene Benzobisoxazole (PBO)/carbon/glass), and (b) strengthening configuration (NSE/ Externally-Bonded (EB)). Amongst the three FRCM materials, the PBO-FRCM system offered the highest strengthening effectiveness (i.e., highest gain in the load carrying capacity). The average gain in the load-carrying capacity was $45 \%$ and $58 \%$ for the NSE- and EB-FRCM strengthened beams, respectively, compared to the reference (i.e., non-strengthened) specimen. Nonetheless, the results showed a clear advantage for NSE-FRCM strengthening systems over those externally bonded in terms of ductility performance. The advantage of NSE over EB strengthening was also demonstrated by the improved FRCM/concrete bond associated with NSE-FRCM application.
\end{abstract}

Keywords: Reinforced concrete; Near surface embedded; Fabric reinforced cementitious matrix; Flexural strengthening; Externally bonded

\section{INTRODUCTION}

Fabric Reinforced Cementitious Matrix (FRCM) systems have been recently introduced as a viable solution for strengthening Reinforced Concrete (RC) structures. FRCM systems are consisted of high strength fabrics embedded in inorganic cementitious matrices and Externally Bonded (EB) to the RC structures to enhance the performance. The use of inorganic matrices has favored FRCM systems with advantages such as the ability to be applied on wet surfaces and compatibility with the concrete substrate (Lee et al., 2013; Raoof et al., 2017). FRCM is also known as Textile Reinforced Concrete (TRC) (Yin et al., 2014), and Textile Reinforced Mortar (TRM) (Younis et al., 2017a).

FRCM has been proven successful in strengthening RC beams in shear (GonzalezLibreros et al., 2017; Younis et al., 2017b), and flexure (Ebead et al., 2016; Koutas et al., 2019). It has also been noticed that the substrate surface preparation technique implemented could have a significant effect on the performance of FRCM strengthening 
(Ebead \& Younis, 2019). The most commonly implemented substrate surface preparation technique is sandblasting the surface and removing a thin layer of fine grain concrete to avoid any bond deficiencies caused with the FRCM composite and provide a rough surface for bonding as recommended by the ACI 549 guidelines (ACI Committee 549, 2013). This technique however, poses safety risks during sandblasting and necessitates protective action (United States Department of Labor, 2014). Wakjira \& Ebead (2018) introduced a new surface roughening method allowing the safe and easy application of FRCM embedded within the concrete cover called Near Surface Embedded FRCM (NSE-FRCM) (Wakjira \& Ebead, 2018). The NSE technique involves embedding the FRCM into a prepared groove, thus, preserving the RC beam dimensions and enhancing the shear capacity. The results of NSE compared favorably to the traditional EB strengthening and provided improved bonding with the concrete substrate.

It is interesting therefore to study the efficacy of the NSE-FRCM technique in enhancing the flexural capacity of RC beams. To achieve this, seven RC beams were prepared and tested under four-point loading. Three different FRCM fabric materials were employed in preparing the test specimens, namely, carbon, PBO, and glass. Six $\mathrm{RC}$ beams were strengthened using EB and NSE techniques to facilitate comparison between these techniques.

\section{METHODOLOGY}

\subsection{Material properties}

Seven specimens were cast with the same ready-mixed concrete batch with 28day compressive strength of $39.5 \mathrm{MPa}$. The longitudinal reinforcement of the beams had a yield strength of $520 \mathrm{MPa}$ and a corresponding strain of $0.27 \%$. The transverse reinforcement had a yield strength of $535 \mathrm{MPa}$ with a $0.26 \%$ strain value. The materials employed in the strengthening procedure were three different FRCM systems, which are: PBO-FRCM, Carbon-FRCM (C-FRCM), and Glass-FRCM (G-FRCM). Each FRCM system is composed of textile with an accompanying mortar mixed according to the manufacturers' recommendations (Ruredil, 2016a, b; SIKA, 2016). The mechanical properties and geometric information for the different FRCM systems are presented in Table 1 provided by their manufacturers (Ruredil, 2016a, b; SIKA, 2016). Table 1 lists the mechanical and geometric properties of the FRCM fabrics consisting of the centerto-center spacing between fabric strands in warp direction, fabric area per unit width $\left(A_{f}\right)$, fiber modulus of elasticity $(E)$, fiber tensile strength $\left(F_{t u}\right)$, and ultimate strain $\left(\varepsilon_{u l t}\right)$ for each type of FRCM used.

Table 1: Mechanical and Geometric properties of FRCM textiles

\begin{tabular}{|c|c|c|c|c|c|}
\hline Material & $\begin{array}{c}\mathbf{c} / \mathbf{c} \text { spacing } \\
(\mathbf{m m})\end{array}$ & $\begin{array}{c}A_{f} \\
\left(\mathbf{m m}^{2} / \mathbf{m m}\right)\end{array}$ & $\begin{array}{c}\boldsymbol{E} \\
(\mathbf{G P a})\end{array}$ & $\begin{array}{c}\boldsymbol{\varepsilon}_{\text {ult }} \\
\mathbf{( \% )}\end{array}$ & $\begin{array}{c}\boldsymbol{F}_{\text {tu }} \\
(\mathbf{G P a})\end{array}$ \\
\hline Carbon & 10 & 0.0470 & 240 & 1.8 & 4.8 \\
\hline PBO & 10 & 0.0455 & 270 & 2.15 & 5.8 \\
\hline Glass & 18 & 0.0470 & 80 & 3.25 & 2.6 \\
\hline
\end{tabular}




\subsection{Test specimens and preparation}

A total of $7 \mathrm{RC}$ beams were cast with a cross section of $150 \times 260 \mathrm{~mm}$, and 2500 $\mathrm{mm}$ in length. Two $10 \mathrm{~mm}$ bars were used as tension reinforcement in all beams and two $8-\mathrm{mm}$ bars were used as top reinforcement. The transverse reinforcement was $8 \mathrm{~mm}$ diameter stirrups spaced $100 \mathrm{~mm}$ along the length of the beam. The reinforcement details are shown in Figure 1. One beam served as a control specimen with no strengthening, three beams were strengthened using two layers of FRCM fabric $150 \mathrm{~mm}$ wide applied as EB and three beams were strengthened using the NSE technique with two layers of FRCM fabric $90 \mathrm{~mm}$ wide over the span of the beams. The EB strengthened specimens had the soffit of the beam sandblasted first to remove the fine grain concrete. In order to prepare the NSE strengthened beams, a $90 \mathrm{~mm}$ wide groove was prepared using a slitting machine at the soffit of the beam and the concrete was manually chipped away with a chisel resulting in a rough surface. The depth of the groove was selected based on the manufacturers' recommended mortar thickness that accommodates two layers of FRCM fabrics. The test matrix is shown in Table 2. Both NSE, and EB strengthening schemes are shown in Figure 2.

Table 2: Test matrix

\begin{tabular}{|c|c|c|c|}
\hline No. & ID & Strengthening & Fabric \\
\hline 1 & R & - & - \\
\hline 2 & P-N & NSE & PBO \\
\hline 3 & C-N & NSE & Carbon \\
\hline 4 & G-N & NSE & Glass \\
\hline 5 & P-E & EB & PBO \\
\hline 6 & C-E & EB & Carbon \\
\hline 7 & G-E & EB & Glass \\
\hline
\end{tabular}

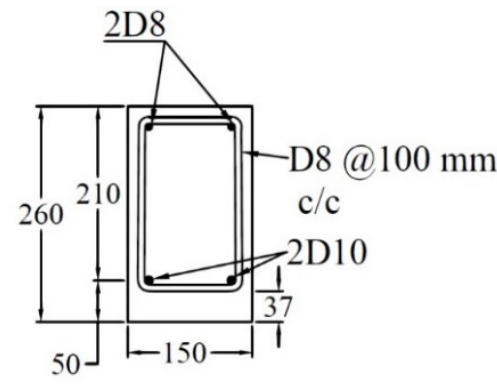

Figure 1: Reinforcement configuration and dimensions $(\mathrm{mm})$

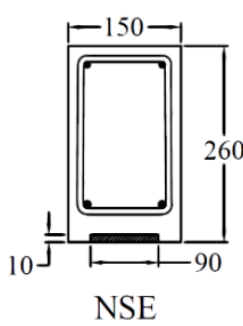

(a)

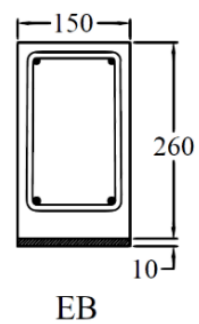

(b)
Figure 2: Strengthening configurations $(\mathrm{mm})$

\subsection{Test setup}

The specimens were tested under four-point loading using a monotonically applied hydraulic load at two points on the beam as shown in Figure 3. The loading was displacement controlled at a rate of $1 \mathrm{~mm} / \mathrm{min}$. The load and midspan deflection measurements were recorded along with the concrete strain at the top, and tension steel strain at the center of the beam. 


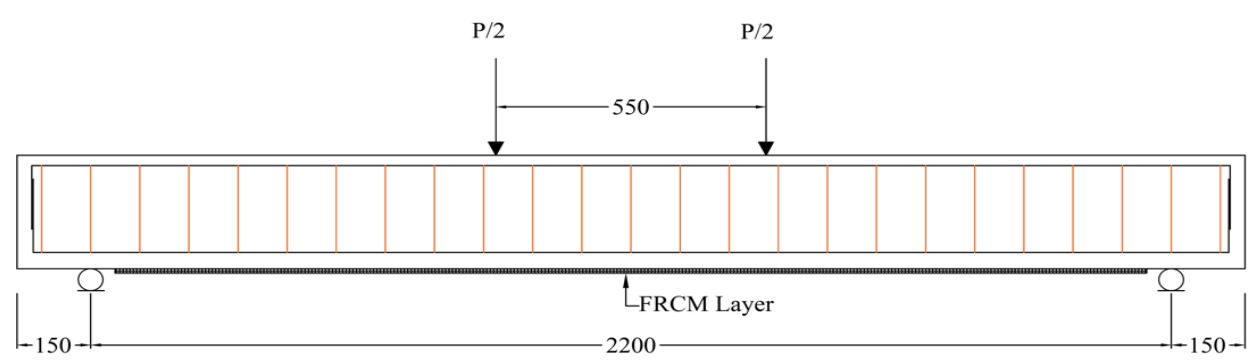

Figure 3: Test setup

\section{EXPERIMENTAL RESULTS}

Table 3 summarizes the experimental results listing the beam names, equivalent axial stiffness $\left(\kappa^{f}\right)$, ductility index $(\Delta I)$, ultimate load $\left(P_{u}\right)$, percentage gain in ultimate load $\left(P_{u}\right.$ gain $)$, and failure mode.

Table 3: Test results summary

\begin{tabular}{|c|c|c|c|c|c|c|}
\hline Beam & $\boldsymbol{\kappa}^{f} \boldsymbol{\kappa}^{f} \mathbf{( M P a )}$ & $\Delta \boldsymbol{I}$ & $\boldsymbol{\delta}_{u} \boldsymbol{\delta}_{\boldsymbol{u}} \mathbf{( m m )}$ & $\begin{array}{c}\mathbf{P}_{\mathbf{u}} \\
(\mathbf{k N})\end{array}$ & $\boldsymbol{P}_{\boldsymbol{u}}$ gain $_{\boldsymbol{u}}$ gain $\mathbf{( \% )}$ & $\begin{array}{c}\text { Failure } \\
\text { Mode }\end{array}$ \\
\hline R & - & 15.31 & 27.2 & 40.0 & - & $\mathrm{A}+\mathrm{B}$ \\
\hline P-N & 24.0 & 5.73 & 28.1 & 62.7 & 56.8 & $\mathrm{C}$ \\
\hline C-N & 29.9 & 3.21 & 16.1 & 59.2 & 48.1 & $\mathrm{C}$ \\
\hline G-N & 13.3 & 5.56 & 22.9 & 52.5 & 31.0 & $\mathrm{D}$ \\
\hline P-E & 38.5 & 4.53 & 25.7 & 68.9 & 72.3 & $\mathrm{E}$ \\
\hline C-E & 47.9 & 3.04 & 16.1 & 68.7 & 71.8 & $\mathrm{C}$ \\
\hline G-E & 21.3 & 3.03 & 13.1 & 51.9 & 29.8 & $\mathrm{D}$ \\
\hline
\end{tabular}

$\mathrm{A}=$ steel yielding, $\mathrm{B}=$ concrete crushing, $\mathrm{C}=$ mid-span delamination, $\mathrm{D}=$ fabric rupture, and $\mathrm{E}=$ plate-end delamination.

\subsection{FRCM composite equivalent axial stiffness}

In order to facilitate the comparison, the equivalent axial stiffness $\left(\kappa^{f}\right)$ is used, which utilizes the amount of FRCM fabric through the given eq. (1) (Ebead et al., 2016):

$$
\kappa^{f}=\rho_{f} E_{f}=\frac{N A_{f} b E_{f}}{b d_{f}}
$$

where $\rho_{f}=$ fabric reinforcement ratio, $N=$ number of layers of fabric, $A_{f}=$ equivalent area of fabric, $b=$ FRCM fabric width ( $150 \mathrm{~mm}$ for EB and $90 \mathrm{~mm}$ for NSE), $d_{f}=$ effective depth of FRCM fabric (265 $\mathrm{mm}$ for EB and $255 \mathrm{~mm}$ for NSE), and $E_{f}=$ cracked FRCM composite modulus of elasticity. Table 4 lists the ultimate tensile stress ( $\left.\sigma_{f u}\right)$, ultimate strain $\left(\varepsilon_{f u}\right)$, and cracked tensile modulus of elasticity $\left(E_{f}\right)$ acquired from tensile characterization tests on FRCM coupons (Younis et al., 2017b). The highest $\kappa^{f}$ values were observed in the C-FRCM strengthened specimens, followed by PBOFRCM and then G-FRCM strengthening specimens. This is due to the high mechanical properties of the C-and PBO-FRCM composites compared to the G-FRCM. The graph 
shown in Figure 4 displays the plots of the gain in $\mathrm{P}_{\mathrm{u}}$ vs. the stiffness factor, A linear trend is observed.

Table 4: FRCM tensile characterization results

\begin{tabular}{|c|c|c|c|}
\hline FRCM & $(\mathbf{\%}) \varepsilon_{f u}$ & $(\mathbf{M P a}) \boldsymbol{\sigma}_{f u}$ & $(\mathbf{G P a}) E_{f}$ \\
\hline Carbon & 1.04 & 1178 & 135 \\
\hline PBO & 1.06 & 1235 & 112 \\
\hline Glass & 0.93 & 767 & 60 \\
\hline
\end{tabular}

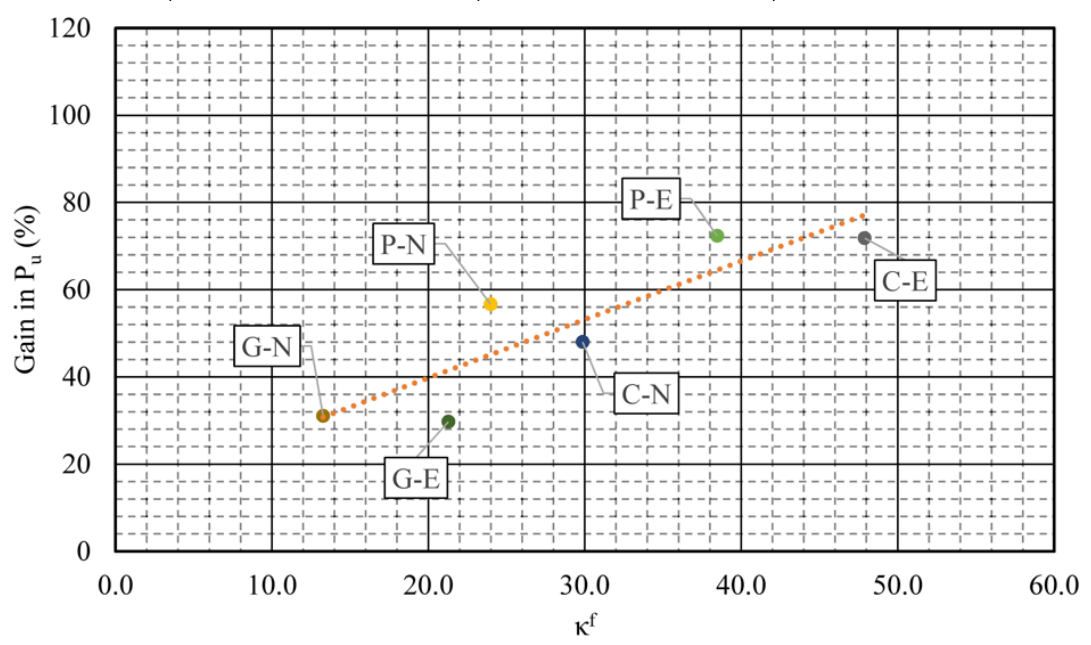

\subsection{Ultimate load carrying capacity}

Figure 4: Gain in $\mathrm{P}_{\mathrm{u}}-\kappa^{f} \kappa^{f}$ plots

It was observed that $\mathrm{PBO}$ resulted in the highest $P_{u}$ with an average value of $64.6 \mathrm{kN}$ for PBO-FRCM strengthened beams (P-N and P-E) which is $64.6 \%$ higher than that of the benchmark specimen R which had a $P_{u}$ value of $40 \mathrm{kN}$. As for the C-and G-FRCM strengthened specimens, the average $P_{u}$ values were $64 \mathrm{kN}$ and $52.2 \mathrm{kN}$, respectively, providing an increase in $P_{u}$ of $60 \%$ and $30.4 \%$, respectively. Upon comparing the different strengthening techniques, it is shown that the average capacity enhancement is close between both NSE and EB strengthening. The average $P_{u}$ of NSE-FRCM and EBFRCM strengthened specimens was $58.1 \mathrm{kN}$ and $63.2 \mathrm{kN}$, respectively, with a difference of about $8 \%$ between them. This shows that NSE strengthening can be a valid alternative to EB strengthening.

\subsection{Ductility performance}

The load-deflection relationships for the beams are represented in Figure 5 and Figure 6 for NSE and EB strengthened beams respectively. The ductility index $(\Delta I)$ which is defined as the ratio of the ultimate deflection $\left(\delta_{u}\right)$ to yield deflection $\left(\delta_{y}\right)$ shows an advantage towards NSE strengthening. The average $\Delta I$ values were 4.8 and 3.5 for 
the NSE strengthened specimens and the EB strengthened specimens, respectively. The increased $\Delta I$ caused by the NSE strengthening compared to the EB strengthening is attributed to the preserved section dimensions and the lower amount of FRCM composite implemented in NSE strengthening. This allowed NSE strengthened specimens to reach higher deflections at ultimate load. As for the fabric type, the average $\Delta I$ values were 5.1, 3.1, and 4.3 for PBO-, C-, and G-FRCM strengthened specimens, respectively, showing the highest ductility for PBO-FRCM followed by G-FRCM and then C-FRCM.

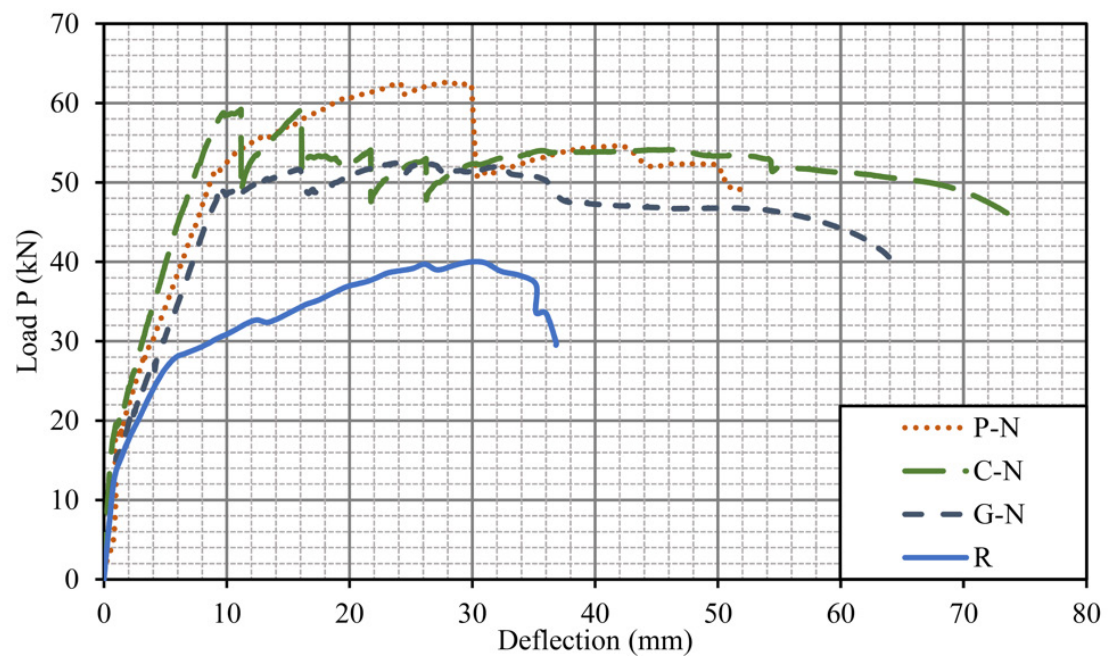

Figure 5: NSE strengthened beams load-deflection graphs

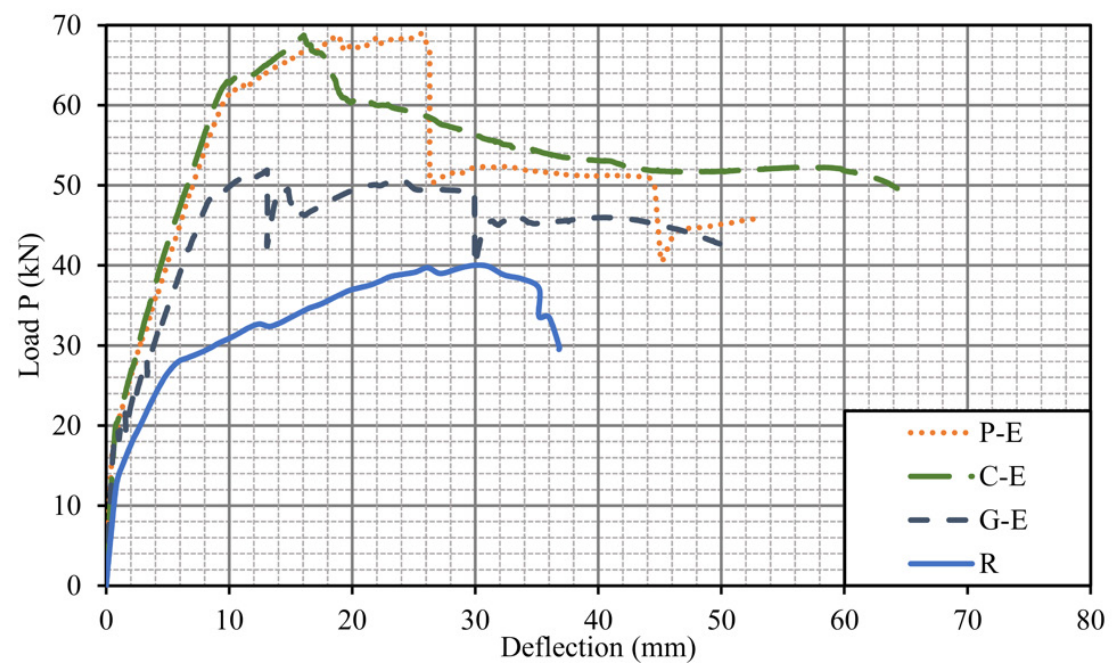

Figure 6: EB strengthened beams load-deflection graphs

\subsection{Failure modes}

The reference specimen $\mathrm{R}$ failed in the typical un-strengthened manner of steel yielding followed by concrete crushing at midspan. The failure mode depended on the FRCM fabric type and strengthening technique. Specimen P-N failed due to midspan 
delamination while its EB counterpart (P-E) failed due to plate end debonding which indicated increased bond efficiency between concrete substrate and FRCM composite due to the NSE strengthening. As for the carbon strengthened specimens (C-N and C-E) the failure was due to midspan delamination, and the glass strengthened specimens (G-N and G-E) failed due to complete fabric rupture indicating maximum FRCM utilization.

\section{CONCLUSION}

This study investigates the efficacy of NSE-FRCM strengthening in enhancing the flexural performance of RC beams. A total of $7 \mathrm{RC}$ beams were prepared and tested in four-point loading. The test parameters were the FRCM fabric material and the strengthening technique. Based on the test results, the following can be concluded:

- The surface roughening of NSE allowed the original section dimensions to be preserved and eliminate the safety risks involved due to sandblasting.

- The average $P_{u}$ values were $58.1 \mathrm{kN}$ and $63.2 \mathrm{kN}$ for NSE and EB strengthened specimens, respectively, indicating favorable performance for NSE strengthening.

- Specimens strengthened using NSE-FRCM exhibited improved ductility performance compared to their EB-FRCM strengthened counterparts.

- NSE strengthening alleviated the plate end debonding in specimen P-N due to the increased bonding performance between FRCM and concrete substrate.

- Glass FRCM strengthened specimens exhibited maximum FRCM fabric utilization, indicated by the failure due to complete fabric rupture.

This study enriches the literature with promising results about the NSE-FRCM technique that can be helpful for future studies on the applications of FRCM strengthening for concrete and masonry structures.

\section{ACKNOWLEDGEMENTS}

This paper was made possible by NPRP grant \# NPRP 7-1720-2-641 from the Qatar national research fund (a member of Qatar Foundation). The findings achieved herein are solely the responsibility of the authors.

\section{REFERENCES}

ACI Committee 549 (2013). Guide to Design and Construction of Externally Bonded FabricReinforced Cementitious Matrix (FRCM) Systems for Repair and Strengthening Concrete and Masonry Structures.

Ebead, U., Shrestha, K. C., Afzal, M. S., El Refai, A. \& Nanni, A. (2016). Effectiveness of fabric-reinforced cementitious matrix in strengthening reinforced concrete beams. Journal of Composites for Construction, 21(2), 04016084.

Ebead, U. \& Younis, A. (2019). Pull-off characterization of FRCM/Concrete interface. Composites Part B, Elsevier, 165, 545-553.

Gonzalez-Libreros, J. H., Sneed, L. H., D’Antino, T. \& Pellegrino, C. (2017). Behavior of RC beams strengthened in shear with FRP and FRCM composites. Engineering Structures, Elsevier Ltd, 150, 830-842. 
Koutas, L. N., Tetta, Z., Bournas, D. A. \& Triantafillou, T. C. (2019). Strengthening of concrete structures with textile reinforced mortars : State-of-the-art review. Journal of Composites for Construction, 23(1), 03118001.

Lee, D., Cheng, L. \& Yan-Gee Hui, J. (2013). Bond characteristics of various NSM FRP reinforcements in concrete. Journal of Composites for Construction, 17(1), 117-129.

Raoof, S. M., Koutas, L. N. \& Bournas, D. A. (2017). Textile-Reinforced Mortar (TRM) versus Fibre-Reinforced Polymers (FRP) in flexural strengthening of RC beams. Construction and Building Materials, The Authors, 151, 279-291.

Ruredil. (2016a). Ruredil X Mesh Gold Datasheet.

Ruredil. (2016b). Ruredil X Mesh C10 Datasheet.

SIKA. (2016). SikaWrap -350G Grid Datasheet.

United States Department of Labor (2014). Protecting Workers from the Hazards of Abrasive Blasting Materials, OSHA FS 3697 - 2014.

Wakjira, T. G. \& Ebead, U. (2018). Hybrid NSE/EB technique for shear strengthening of reinforced concrete beams using FRCM: Experimental study. Construction and Building Materials, 164, 164-177.

Yin, S., Xu, S. \& Lv, H. (2014). Flexural behavior of reinforced concrete beams with TRC tension zone cover. Journal of Materials in Civil Engineering, 26(2), 320-330.

Younis, A., Ebead, U. \& Shrestha, K. C. (2017a). Tensile characterization of textile reinforced mortar. Proceedings of the Ninth International Structural Engineering and Construction Conference, Resilient Structures and Sustainable Construction, ISEC Press, Valencia, Spain.

Younis, A., Ebead, U. \& Shrestha, K. C. (2017b). Different FRCM systems for shear-strengthening of reinforced concrete beams. Construction and Building Materials, Elsevier Ltd, 153, 514526. 